\title{
Online Learning: Trends, Potential and Challenges
}

\author{
Rose Liang, Der-Thanq Victor Chen \\ National Institute of Education, Nanyang Technological University, Singapore City, Singapore \\ Email: rose.liang@nie.edu.sg

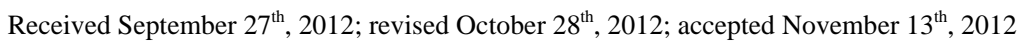

\begin{abstract}
This paper examines trends, potential and challenges in online learning. We consider 6 online learning trends and the issues associated with the trends. These include a one sided emphasis on the technology; physical versus online presences; formal face-to-face versus distance/workplace education; mono-versus multi-lingual online learning; open source versus proprietary software; and the open standard oxymoron. The potential of online learning include 4 factors of accessibility, flexibility, interactivity, and collaboration of online learning afforded by the technology. In terms of the challenges to online learning, 6 are identified: defining online learning; proposing a new legacy of epistemology-social constructivism for all; quality assurance and standards; commitment versus innovation; copyright and intellectual property; and personal learning in social constructivism. The authors contend the necessity of developing new ways of thinking to face the challenges relating to the development of online learning.
\end{abstract}

Keywords: Online Learning; Trends; Issues; Potential; Challenges

\section{Introduction}

Online learning has become an important consideration particularly in higher (Kim \& Bonk, 2006; Al-Adwan \& Smedley, 2012), adult education (Olesen-Tracey, 2010; Cercone, 2008) and also in schools (Cavanaugh, Barbour, \& Clark, 2009; Nicholas \& Ng, 2009). These institutions are engaged in efforts to make online learning engaging and effective to learners. In order to do this, it would be apropos to consider the trends or tendencies of online learning as well as the potential. These trends bring forth new opportunities in light of the potential yet simultaneously pose challenges such as requiring more research and experimentation.

We contend that it is necessary to develop new ways of thinking in face of the trends and challenges presented. In support of our contention, we explore trends in online learning in terms of 6 issues and 4 potentials of online learning and 4 challenges for practitioners to keep in mind when designing online activities and course.

\section{Trends}

\section{Chasing the Technology}

Unfortunately, the most visible issue of online learning is still the focus on technological considerations. Historically, it has always been the case that when a new type of technology arrives, people will try to think of ways to use it in education. This was how slide projectors, overhead projectors, televisions, and computers came onto the school scene. More recently, multimedia and the Internet have dominated the field of education technology. Many research projects have been devoted to finding the effectiveness of these new technologies. The latest development of mobile devices such as the hand phones and PDAs has again aroused interest in so-called mobile learning or m-learning. Continued from the conventional "wisdom" of chasing the development of technologies, it is common to explore how these mobile devices can foster a more flexible ap- proach to learning. Note that we are not suggesting that these technical considerations are unimportant. Rather, we are recommending a more thoughtful approach; we strongly believe with many writers (Smith, 2008) that sound educational foundations, not cutting edge technologies alone, should underpin the development of new approaches to learning.

\section{Physical versus Online Presences}

The predominance of online learning is breaking down traditional physical boundaries and creating a online culture, unique in its own right. We are in a situation where an online presence over the Internet could be more communicative and engaging than a physical presence. In other words, the relative advantages of these two worlds - the physical and the online-are fast converging. According to research, online presence can sometimes be felt by the participants as much more intimate than physical presence. For example, attending a face-to-face lecture may only involve one-way communication whereas an in-depth discourse using a text-based discussion forum can be very interactive. However, we note that richness of media and its technological affordances does not necessitate or guarantee the quality of online learning. This trend in the convergence of physical and online presences is likely to change the way we interact with people.

\section{Formal Face-to-Face versus Distance/Workplace Education}

As a consequence of the trend just noted, the distinction between formal and informal education is fast diminishing. Traditionally, distance education had been perceived as a secondary choice to formal face-to-face education. It was believed that the latter provided more opportunities for students to interact with the teacher and peers (other students) and could, therefore, be more beneficial for learning. However, this conventional advantage no longer holds. The decrease in formal education/tra- 
ining settings resonates with and is congruent with the recent emphasis on authentic workplace learning because of the contextual nature of cognition (Brown \& Duguid, 2000). In most instances, learning can take place in the workplace and in online learning activities that can be more engaging as pointed out earlier. The trend is now towards the mixed-mode approach where opportunities are provided for learners to meet face-toface at certain milestones or points in the course (for an example of this mixed mode approach, see Smith, Reed, \& Jones, 2008).

\section{Mono- versus Multi-Lingual Online Learning}

The English language has dominated the Internet. This dominance provides a common platform for communication but it has also created a divide between those who understand the language and those who do not, that is, those who know English are likely to enjoy the benefits of online learning. Due to recent developments in multi-lingual technology, it is now possible to access the Internet using one's native language. Consequently, the dominance of English is gradually fading in light of this trend. Those who do not speak English can increasingly access resources and online learning in their native languages. Currently, there are intelligent Web pages which are able to detect the preferred language of the user and to present information in that particular language. These systems are in their infancy (the accuracy of interpretation is still the main developmental bottleneck) and the implications of these developments are still largely uncertain. Ideally, these interpreting systems would diminish English language dominance and grant access to more people. However, the tradeoff is that the common communication platform is gradually disappearing. It is still debatable whether or not we should maintain the development of both of these two seemingly opposing trends.

\section{Open Source versus Proprietary Software}

The open source movement aims to tackle the long-term sustainability issue of any major development project. Open source invites people to use the developed system and grants people access to the source codes free of charge. People are free to develop the system further based on their needs in their respecttive local contexts. To prevent there being too many versions of the same system (with minor differences), a consortium will usually be set up to host the "authoritarian" version of the system. Only approved additions will become part of this "authoritarian" version. Long-term sustainability is therefore secured by the many participants from all over the world. The risks and development costs are also shared by the consortium participants.

However, there is a proviso. Even though development costs and risks are shared, maintenance may cost more (due to the programming bugs, etc.), and there is no guaranteed long term development once individual institutions may run out of money and decide to withdraw from the consortium. In contrast, the proprietary products have characteristics of lower maintenance, higher upfront capital commitment and are less easily customised applications in local contexts. The debate between open source and proprietary software is likely to continue for some time.

\section{The Open Standard Oxymoron}

Among all the online learning initiatives, the Open Standard movement is the underlying theme. There is a trend to great emphasis on developing learning objects, which conform to an open standard so that they can be shared within education sectors. One problem in regard to this issue of "standard" is whose "open standard" do programmers of online learning follow? For example, IMS or IEEE for learning objects? HTML or XML for web pages? How do we prevent history from repeating itself? The infamous war between beta and VHS video tapes is a classic example of how "standards" can divide. The term "open standard" itself is an oxymoron. How can a standard be open since one must follow a particular standard? One is either in or out. Paradoxically, standards are always closed, are they not? The issue of standard is not likely to go away. History has taught us not to keep standards closed, because once we are stuck in a fixed standard, innovations are stifled. However, keeping a standard open is prone to much additional administrative and coordination efforts. Probably a radically different approach is needed.

In the above sections, we have articulated online trends and some of the implicit issues which underpin these trends. With regard to decisions made and any direction taken, there are usually pros and cons to any implementation. We hope the reader will be able to recognise the assumptions which accompany each direction. However, we also wish to highlight the unexplored potential in the development of online learning.

\section{Potential}

In our mind, the potential of online learning lies in four factors: accessibility, flexibility, interactivity and collaboration.

\section{Accessibility}

The very first step to online learning is access (Salman, 2002). No matter how well the instruction is designed, if the learner cannot gain access to the course learning materials via the technology due to physical or financial constraints, the instructional design is rendered useless and non-existent. This is especially true for continuing education or staff training. In the past, training has been predominately conducted outside of the workplace context such as in training schools and centerscommonly referred to as formal training settings. Increasingly, this ready access to learning materials and to Internet has the potential to blur the distinctions between formal and informal training. Today's emphasis on "on-the-job” training with available resources via the Internet is diminishing this virtuality divide between formal and informal training.

\section{Flexibility}

A second potential of online learning is flexibility. For example, traditional distance education relies heavily on paperbased materials. Interactions are supplementary to content and are commonly achieved via telephone conferencing. Video conferencing came onto the scene in recent years. However, this technology is expensive and seldom interactive and therefore never very popular. There are at least two problems: the set-up of videoconferences is expensive and it only makes the place flexible, but not in terms of time or timings. That is, people must be together at the same time for the interaction to take place. With the use of the Internet, interaction with people can now achieved with a very cheap set-up. Nowadays, anyone with access to the Internet can participate in e-tivities (Salmon, 
2002). In addition, because these e-tivities are asynchronous in nature, they give learners the flexibility of when to participate and now they have more time to process the materials before they respond.

It should be noted, however, that flexibility always comes at a price (Chen, 2003). Highlighting one aspect of flexibility will inevitably make other aspects inflexible. For example, in order to create a sense of learning community, all students will need a fixed timeframe to interact with one another. This inevitably imposes inflexibility on the time. If we want flexible time and space, we will have to compromise on the flexible content. If we want a flexible pace, we will have to forgo the ease of flexible access to resources and experts (for they are not always available).

\section{Interactivity}

Interactivity and online learning are separate issues although online learning environments can be interactive-that is, the learning environment allows learners and users to interact actively with the objects in the online environment. Interactivity is not just an issue with the user-interface but also involves the design of the learning environment. If the design is learnercentered, it caters for learner-involvement such as learner-navigation and exploration-aligned to constructivist notions of learning. The proliferation of applications that makes it easy for programmers to design for interactive environments facilitates such active forms of learning environments. Interactivity also involves people interacting with people via the Internet in the context of online learning. The various communication tools afforded by online learning management systems foster instructor-to-student as well as student-to-student interactions.

\section{Collaboration}

While interactivity deals primarily with inter-actions with the learning environment, collaboration is a construct that encourages learners to work with other learners on a common project or activity that an individual alone would find difficult to complete. Social collaboration between individuals is now recognized by many educators and researchers as an integral process in online learning rather than just as an instructional strategy. In this process, humans are viewed as social beings not just as individual beings. Because they have access to resources and experts and learners from different backgrounds and places, students are presented with more opportunities for collaboration.

\section{Challenges}

Having reviewed the trends and potential of online learning, we articulate challenges which we recognize as important to online learning and its proliferation. We describe possible challenges which currently confront our quest for quality online learning.

\section{Whose Definition of Online Learning?}

Increasingly, we are witnessing a host of different online learning definitions: from those that include CD-ROMS to web-based applications, etc. It seems that the medium of delivery often drives the definition. One reason for this is the strong push from commercial companies to sell their products and services. Online learning is an evolving phenomenon, and as companies and academics in universities attempt to make sense of this trend, we need to construct definitions on a common platform. We believe that the definition of online learning must seriously consider issues such as what learning is, how learning occurs through e-means and the implications that online learning pose for flexibility, accessibility, interactivity, and collaboration.

\section{A New Legacy of Epistemology—Social Constructivism for All?}

Underpinning many of the online learning developments, a similar orientation towards implicit or explicit notions of active learning and social constructivism is evident, for example in Computer-Mediated Communication (Romiszowski \& Mason, 1996) and in the Santally, Rajabalee, and Cooshna-Naik (2012) study to design and implement a social-constructivist environment for distance e-learning. Constructivism and social constructivism seem most popular and relevant as the emerging theoretical underpinnings of these online learning developments. Our concern is that we may be creating yet another legacy of learning that seems to be value-laden in terms of its benefits rather than its limitations. The tension between the newer approaches (e.g., constructivism and active learning) and the traditional (e.g., didactic) is increasing because of distinctive learning paradigms. We would like to maintain that there is a place for differing paradigms of learning, including the cognitivist or even behaviorist approaches (Hung \& Chen, 2000).

\section{Quality Assurance and Standards}

The number of online learning courses is increasing rapidly. However, due to the ill-defined nature of online learning, the quality of online learning courses vary. There is a well-established (though not perfect) structure to safeguard quality of transitional face-to-face courses. The workload for both the teacher and the student, and how the course is charged can be defined (with limitations). In online learning, activities can happen at any time of the day. Reporting to the classroom or for work becomes irrelevant. The so-call standards of practice and quality will need to be reconsidered and perhaps require a paradigm shift in our thinking.

\section{Commitment versus Innovation}

Online learning is still a developing field. Tools involved in the learning process such as learning management systems are constantly changing. Before an institution can comfortably settle on a decision to commit to a system, a better product appears on the market. It is always a difficult decision to commit to a system. This is exacerbated by financial considerations, since most often the financial commitment to such a system is not insubstantial. Once many online learning courses use the chosen system, the institution will face the obligation to stick with it, or the investment in the design and development of the courses may be wasted. This poses a problem. On the one hand, the institution needs to commit to the same product to ensure its longer-term development in online learning. On the other hand, the institution should also be constantly looking for better solutions. Perhaps, the latest innovation will meet their needs better. How much can one single institution afford to try and experiment with new systems? 


\section{Copyright and Intellectual Property}

Another key challenge of online learning is copyright. The very ethos of the Internet, that is to share, is almost the opposite philosophy to that of copyright and intellectual property. In education, we constantly need access to existing work, be it papers, artworks, etc. It becomes a logistical nightmare to ask for permission to use every single material used in a course. However, if we simply make copies for students or upload it on a password-protected web site, existing copyright law may still be infringed. We need a new set of rules to govern these copyright and intellectual property issues.

In addition, due to the collaborative nature of online learning, most courses are now no longer developed by just one instructor. Usually, a team consisting of the instructor, the instructional designer, the programmer and the graphic artists is involved. Most of them are being paid to develop the courses. So, whose intellectual property is it, the institution, the key members of the team, or everybody who was involved? There does not seem to be an easy answer.

\section{Personal Learning in Social Constructivism}

Finally, from a learning psychology perspective, individual or personalized learning (Polanyi, 1964), in our opinion, needs to be balanced with the social dimensions of learning. Currently, there is a swing towards social levels of learning because of the trend towards social-cultural dimensions. However, it is necessary to balance this with the Piagetian notion that learning is ultimately a change in behaviour individually (Chen \& Hung, 2002; Hung \& Nichani, 2001). How do we know that online learning environments designed for social collaborations will ultimately lead to a change of thinking, understanding, and behaviour of the individual as noted by Redecke (2009). Clearly, more research is needed. For example, studies such as Jou and Shiau's (2012) which designed web-based learning systems for self-directed learning and another one (Jou \& Wu, 2012) for self-reflection is a move in this direction of bringing back the individual within the social-cultural dimension in learning.

\section{Summary}

In this paper we have introduced the current trends of development in online learning. They are:

- Chasing the technology.

- Convergence of face-to-face and distance education.

- The joggling between monolingual and multilingual online learning.

- The war between open source software and proprietary software.

- Open source vs proprietary software.

- The open standard oxymoron.

We also briefly discussed four factors of the potential of online learning, namely, accessibility, flexibility, interactivity and collaboration.

Based on our analysis of the trends and the potential, we highlight challenges that currently confront online learning. They are:

- Whose definition of online learning?

- A new legacy of epistemology—social constructivism for all?
- Quality assurance and standards.

- Commitment versus innovation.

- Copyright and intellectual property.

- Personal learning in social constructivism.

\section{REFERENCES}

Al-adwan, A., \& Smedley, J. (2012). Implementing e-learning in the Jordanian higher education system: Factors affecting impact. International Journal of Education and Development Using Information and Communication Technology, 8, 125-135.

Brown, J., \& Duguid, P. (2000). The social life of information. Boston: Harvard University Press.

Cavanaugh, C., Barbour, M., \& Clark, T. (2009). Research and practice in K-12 online learning: A review of open access literature. The International Review of Research in Open and Distance Learning, 10.

Cercone, K. (2008). Characteristics of adult learners with implications for online learning design. AACE Journal, 16, 137-159.

Chen, D. (2003). Uncovering the provisions behind flexible learning. Educational Technology \& Society, 6, 25-30.

Chen, D., \& Hung, W. L. (2003). Is dialogue the method of choice in collective communication? A response to Banathy. Educational Technology, 43, 61-62.

Chen, D., \& Hung, W. L. (2002). Personalised knowledge representations: The missing half of online discussions. British Journal of Educational Technology, 33, 291-299. doi:10.1111/1467-8535.00263

Hung, W. L., \& Chen, D. (2003). Online learning and information technology in the Asia-Pacific region: Perspectives, issues \& divides. Educational Technology, 43, 5-9.

Hung, D., \& Nichani, M. (2001). Constructivism and e-learning: Balancing between the individual and social levels of cognition. Educational Technology, 41, 40-44.

Jou, M., \& Shiau, J.-K. (2012). The development of a web-based selfreflective learning system for technological education. The Turkish Online Journal of Educational Technology, 11, 165-171.

Jou, M., \& Wu, Y.-S. (2012). Development of a web-based system to support self-directed learning of micro-fabrication, technologies. Educational Technology \& Society, 15, 205-213.

Kim, K., \& Bonk, C. (2006). The future of online teaching and learning in higher education: The survey say. Educase Quarterly, 29, 22-30.

Nicholas, H., \& Ng, W. (2009). Engaging secondary students in extended and open learning supported by online technologies. Journal of Research on Technology in Education, 41, 305-328.

Olesen-Tracey, K. (2010). Leading online learning initiatives in adult education. Journal of Adult Education, 39, 36-39.

Polanyi, M. (1964). Personal knowledge: Towards a post-critical philosophy. New York: Harper \& Row.

Redecker, C. (2009). Review of learning 2.0 practices: Study on the impact of web 2.0 innovations on education and training in Europe. European Commission, EUR23664, 1-122, URL (last checked 18 December 2012).

http://ipts.jrc.ec.europa.eu/publications/pub.cfm?id=2059

Romiszowski, A. J., \& Mason, R. (1996). Computer-mediated communication. In D. Jonassen (Ed.), Handbook of research for educational communications and technology (pp. 438-456). New York: Simon \& Schuster Macmillan.

Smith, B., Jones, C., \& Reed, P. (2008). Mode neutral pedagogy. European Journal of Open, Distance and E-learning, 2, 1-6.

Salmon, G. (2002). E-tivities: The key to active online learning. London: Kogan Page Ltd.

Santally, M. I., Rajabalee, R., \& Cooshna-Naik, D. (2012). Learning design implementation for distance e-learning: blending rapid e-learning techniques with activity-based pedagogies to design and implement a socio-constructivist environment. European Journal of Open, Distance and E-Learning, 2, 1-6. 